University for Business and Technology in Kosovo

UBT Knowledge Center

UBT International Conference

2016 UBT International Conference

Oct 28th, 9:00 AM - Oct 30th, 5:00 PM

\title{
Development of Airships Stratospheric Platform Systems (SPS)
}

Dimov Stojce llcev

Durban University of Technology, ilcev@dut.ac.za

Follow this and additional works at: https://knowledgecenter.ubt-uni.net/conference

Part of the Communication Commons, and the Computer Sciences Commons

\section{Recommended Citation}

Ilcev, Dimov Stojce, "Development of Airships Stratospheric Platform Systems (SPS)" (2016). UBT

International Conference. 54.

https://knowledgecenter.ubt-uni.net/conference/2016/all-events/54

This Event is brought to you for free and open access by the Publication and Journals at UBT Knowledge Center. It has been accepted for inclusion in UBT International Conference by an authorized administrator of UBT Knowledge Center. For more information, please contact knowledge.center@ubt-uni.net. 
Book of Proceedings

International Conference on Computer Science and Communication Engineering

\title{
Development of Airships Stratospheric Platform Systems (SPS)
}

\author{
Dimov Stojce Ilcev \\ Durban University of Technology (DUT) Durban, South Africa. \\ ilcev@dut.ac.za
}

\begin{abstract}
In this paper are introduced airships as part of new Stratospheric Platform System (SPS) in function of space communications. Airships are the latest space techniques with advanced technology for fixed and all mobile applications, including military and rural solutions. This SPS employ unmanned or manned, solar or fuel energy airships or aircraft carrying payloads with transponders and antennas. The airship SPS can be considered as a novel solution for providing communication and navigation services. The research and development of airships for putting the system in to practical use is ongoing in some countries. The remote controlled-solar powered airships or aircraft offer a much more cost effective solution for coverage of some region or country including urban, suburban, rural areas, farms and other environments with low population densities. The airship network offers a better solution than existing cellular radio systems, with greater speed of transmission than even ground optical modes. An airship roaming is enhanced without severe shadowing problems and disturbances inside buildings, and the service costs less. The airships mission today can be integrated with current Satellite or cellular systems. This space solution is more autonomous and discrete and will be good solution for rural, military and all mobile applications.
\end{abstract}

Keywords: SPS, TAO, Airship, Gateway, GES, Users

\section{Introduction}

The airships also known as High Altitude Platforms (HAP) are space stations located at an altitude between 20 and $50 \mathrm{~km}$ and at a specified, nominal, fixed or stationary point in stratosphere relative to the Earth. Wireless Communications System (WCS) via SPS becomes the focus of world's attention, which can provide multimedia service to users with high-speed Voice, Data and Video over IP (VDVoIP). The necessity and importance of new SPS wireless communication infrastructures which can provide high-speed multimedia mobile communication service to users who are not satisfied with low-speed data and voice service provided by existing wireless network are rapidly increasing.

The SPS airship is a quasi-stationary vehicle filled with helium, which floats and operates in the stratosphere. At the same altitude SPS aircraft also can be remotely operated or auto controlled as lightweight planes, which need to fly in a circular path, are generally referred to as Unmanned Aerial Vehicles (UAV) platforms.

The SPS airships are air vehicles that provide a platform for scientific, military or commercial payloads at typical heights of 20 to $50 \mathrm{~km}$ in stratosphere layer, which is well above civil air routes, jet streams, and clouds, but substantially below orbiting satellites. The SPS airship stations have similarities and as well as differences with Terrestrial Telecommunication Systems (TTS) 
Development of Airships Stratospheric Platform Systems (SPS)

and Satellite Communications Systems (SCS), the most important of which are summarized in Table 1.

Table 3. Comparison of Data Density and Signal Delays

\begin{tabular}{|c|c|c|c|c|}
\hline \multirow[t]{2}{*}{ Node Type } & \multicolumn{2}{|c|}{ Node Data Density } & \multicolumn{2}{|c|}{ Round Trip Delay } \\
\hline & 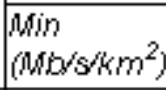 & $\begin{array}{l}\text { Max } \\
\left(\mathrm{Mb} / \mathrm{s} / \mathrm{km}^{2}\right)\end{array}$ & $\begin{array}{l}\text { Min } \\
\text { (milisec) }\end{array}$ & $\begin{array}{l}\text { Max } \\
\text { (milisec) }\end{array}$ \\
\hline LMDS & 3 & 30 & 0.003 & 0.060 \\
\hline $\begin{array}{l}\text { Halo } \\
\text { LEO } \\
\text { (Broadband) } \\
\text { GEO }\end{array}$ & $\begin{array}{l}2 \\
0.002 \\
0.0005\end{array}$ & $\begin{array}{l}20 \\
0.02 \\
0.02\end{array}$ & $\begin{array}{l}0.10 \\
2.50 \\
200\end{array}$ & $\begin{array}{l}0.35 \\
7.50\end{array}$ \\
\hline
\end{tabular}

The SPS network offers better solutions than all cellular and wireless systems, with greater speed of transmission than even optical modes, roaming will be better, without shadowing problems and disturbances inside buildings and service will cost less. In fact, the SPS platform mission can be integrated with current satellite and cellular systems; the system is more autonomous and discrete and will be the best for military and all mobile applications. For instance, the Halo Broadband GSPS Millimetre Wavelength (MMW) Network of the Angel Company provides data densities nearly one thousand times higher than proposed satellites, which scenario is presented in Table 1, while having round trip time delays appropriate for interactive broadband services. Whereas, the delays through satellite network nodes, even through LEO satellite nodes are too long for many interactive applications.

As Table 1 presents, in total delays is 25 or 1,000 times longer for Low Earth Orbit (LEO) or Geostationary Earth Orbit (GEO) then for Halo Networks, respectively. At this point, the Halo comparison parameters are similar to a variety of metropolitan environment spectrum used bands of the Local Multipoint Distribution Service (LMDS) band near $28 \mathrm{GHz}[1,2,3]$.

\section{TAO (SkyNET) Airship Network}

A Research and Development (R\&D) program on a SPS airship system is in progress since April 1998. The final goal of this project is to realize the SPS airship platform system, being capable of an acceptable long-duration station-keeping flight at a stratospheric altitude of about $20 \mathrm{~km}$.

The achievements will enable advanced wireless fixed and mobile communications, digital direct and relay broadcasting, mobile broadband and multimedia transmission, high-speed Internet, high-resolution observations and monitoring of the remote, rural, regional and global environment.

The advanced developments of stratospheric airship in particular and SPS systems technology program in general are recently promoted in many countries worldwide. For instance in Japan is provided collaboration between the Communications Research Laboratory of Japan (CRL), National Space Development Agency of Japan (NASDA) and Japan Marine Science and Technology Centre (JAMSTEC), including the Telecommunications Advancement Organization (TAO) of Japan.

\subsection{Airship Platform System Description}

The stratospheric platform is an unmanned airship kept at a stratospheric altitude of about 20 to $25 \mathrm{~km}$ for broadcast and multimedia communications and Earth observation purposes. The SPS 
Book of Proceedings

International Conference on Computer Science and Communication Engineering

airship station in stratosphere can be equipped with corresponding communications payload, observation sensors and other necessary flight equipment. Thus, with the aim of quickly developing an SPS platform has great potential, so many research institutions in Japan began conducting the relevant research work in 1998. The SPS system is designed similar to a satellite space segment as a relay station to receive signals from ground stations (Gateways) using feeder links and to retransmit them to subscribers using service links.

Therefore, an airship like a satellite is carrying a payload with corresponding transponders and antenna system. At any rate, the launch of SPS into position is much simpler than putting a satellite into any orbit. After careful preparation in the hanger space, the airship is launched in 4 Ascent phases through the troposphere and interface location point in the stratosphere and finally, it will be shifted to the final stage at station-keeping position. In contrary, the recovery phase for planned maintenance goes in the opposite direction, namely, the airship is slowly moved from the station-keeping position towards the Interface point and from there descends down to the ground in 4 descent phases. The airship construction has a semi-rigid hull of ellipsoidal shape, with an overall length of about $200 \mathrm{~m}$, which is shown in Figure 1.

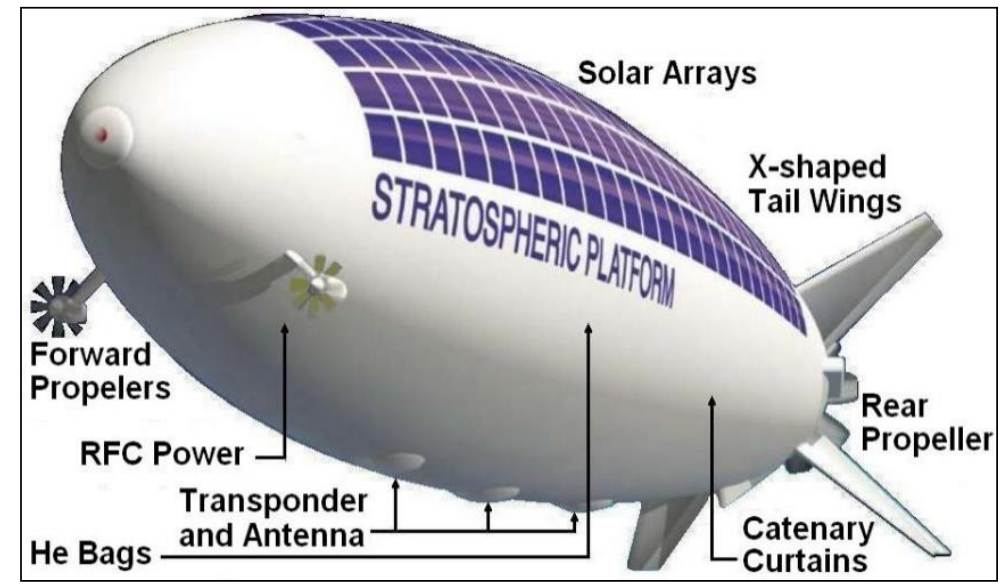

Fig. 1. TAO Airship with Main Components [2]

Platform is composed of an air-pressurized hull for maintaining a fixed contour and internal special bags filled with the buoyant helium gas. Two air ballonets are installed inside the hull to keep the airship at a required attitude. For a load balance to the lifting force, catenary curtains are connected to the lower rigid platform's keel and are directly attached to the envelope. Propulsive propellers are mounted on both the stem and stern of the airship and tail fins are installed on the rear and of the hull. In fact, a solar photovoltaic power system of solar cells and Regenerative Fuel Cells (RFC) is provided to supply a day and night cycle of electricity for airship propulsion. The length of an airship in general is about $250 \mathrm{~m}$ and $60 \mathrm{~m}$ diameter. This is about 4 times as long as Jumbo jet passenger airplanes and so its weight is about 32 tons. However, $50 \%$ of the weight corresponds to those of structures and membrane materials. Solar arrays and fuel batteries, related to the electric power subsystem, are also heavy. And the weight of mission equipment is supposed to be about 1 ton.

The necessary condition for an airship to float at a certain altitude is that the gravity and buoyancy forces, which are exerted on the airship, are in a state of equilibrium. When the shape and volume of the airship are supposed to be constant, unlike a balloon, the buoyant force at an altitude of 20 $\mathrm{km}$ becomes about 1/15 that at sea level. Accordingly, a buoyancy of 15 times as much is necessary for equilibrium. Therefore, in order to float a SPS in the stratosphere, it is necessary to 
make the weight of the airship light and to make the buoyancy as large as possible. Inside the airship there are several internal bags filled with He gas to obtain enough buoyancy.

The airship stratospheric station can provide observation, monitoring, surveying and communication service, so adequate demands can be expected in the near future. The SPS system has lots of advantages over the conventional wireless communication infrastructure and satellite communications systems. The SPS has the advantages of both SCS and TTS featuring flexibility of network planning and construction, wide bandwidth, wide coverage, easy maintenance and so on $[2,3,4]$.

\subsection{Outline of the Tracking and Control System}

In order to operate unmanned SPS airship safely, it will be necessary to construct an adequate tracking and control system and establish operational technique on board the platform and on the ground. However, based on SPS system technologies, appropriate countermeasures can be taken in time regarding observation and prediction of weather situations in stratosphere and to do monitoring of operational conditions of onboard equipment, and even to provide standards regarding safety and security of dangerous atmospheric phenomena or abnormal performances of onboard equipment. At this point, the TAO airship system has to develop adequate TT\&C solutions onboard the platform and on the ground as well.

During launch airships can be strongly affected by wind, therefore, when the preliminary decision for launching or recovering to the ground of an airship is to be made, it is necessary to predict the weather forecast data, especially wind direction and speed, in advance and estimate whether:

1) The airship may deviate from the area, within which the tracking and control system works effectively and

2) The launch of SPS airship or recovery to the ground has to be conducted safely.

Based on all this estimations, a final decision with regards launching or recovery has to be made. After the last checks, the airship is released towards position in stratosphere. It starts to ascend upwards due to the effects of the buoyancy. Near the tropopause, which is the layer between the troposphere and stratosphere, airship continues to ascend, being drifted by the jet stream. Finally, the airship arrives in transfer position at an altitude of about $20 \mathrm{~km}$. After this operation, the airship is moved to the geo station-keeping position and the mission operation is started.

Once an airship is launched, it can be used for a maximum of three years. Namely, an airship is periodically, about every three years, recovered and the $\mathrm{He}$ gas and onboard equipment condition is checked. Moreover, after these routine checks, it is launched again. The life of an airship is supposed to be more ten years $[1,3,4]$.

\section{Airship Space Segment and Network Coverage}

In the last two decades there have been organized several developments in the space platforms arena of airship scenario for broadcasting and broadband communications. In that manner, the special effort is provided for design of data transfer and surveillance system on many international borders via airships with deployment and demonstration of reliable and proven wireless technology. Thus, a number of trials of small-scale airship have been conducted by companies in Japan, USA and Switzerland (StratoComm) were involved in these projects. Several programs are now focusing on airship (HAP) for fixed and mobile wireless broadband using local WiMAX and WiFi services. In the interim, StratoComm formed in 1992 has designed HAP network for Transitional Telecommunication Project (TTP) purpose. This TTP network became commercially for communications serving about half million users seamless transition 
Book of Proceedings

International Conference on Computer Science and Communication Engineering

from the aerostat-based systems to its SPS (HAP) network to serve about three million customers, which coverage is shown in Figure 2.

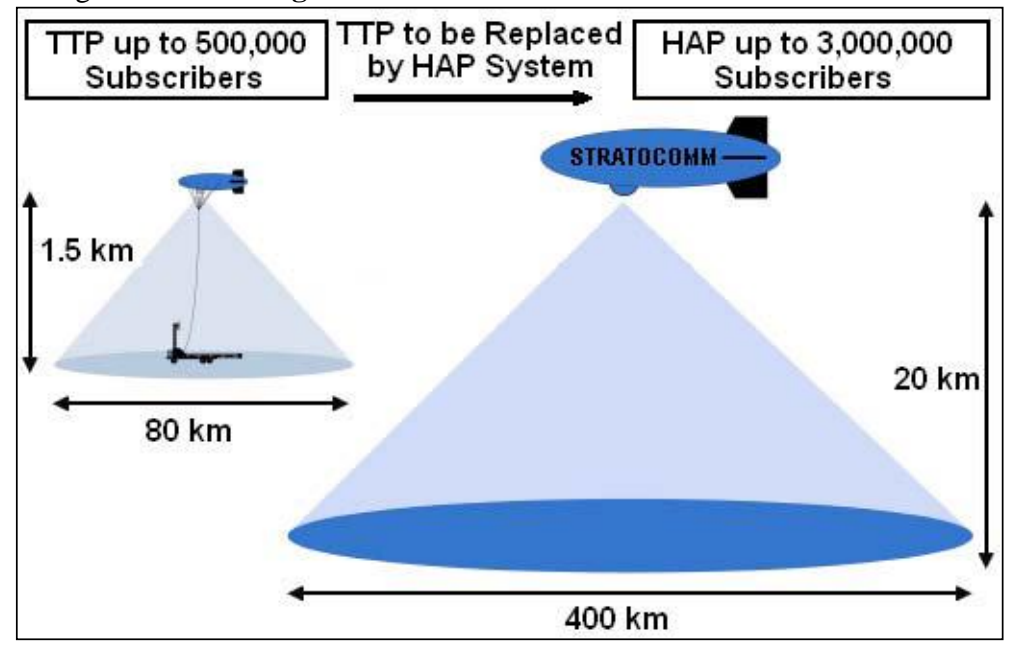

Fig. 2. Transition from TTP to SPS Airship "StratoComm" [2]

The StratoComm TTP space platform is a Lighter-Than-Air (LTA) aerostat platform system positioned at an altitude point of approximately 1,500 meters over the region to which it is providing wireless telecommunications services. The aerostat is connected via high-strength steel and Kevlar tether to the ground cite, thereby maintaining its position and ability to support subscriber services, as well as providing access to power, operational control and data service via fiber optic cable and electrical conductors embedded within the tether.

The transitional aerostat station is approximately 37 meters in length and 12 meters at its widest point. It meets the US Federal Aviation Administration (FAA) all requirements, including the presence of an emergency flight termination system and proper lighting. The aerostat platform carries an internally designed payload with telecommunications transponder weighing approximately $225 \mathrm{~kg}$, which is capable of supporting subscribers by broadband fast Internet, Voice, Data and Video (VDV) transmission with various combinations in a coverage area of 80 $\mathrm{Km}$ in diameter.

As is shown in Figure $\mathbf{2}$ is provided transition from the old TTP to more advanced SPS system. The SPS station doesn't interfere aircrafts flights, because SPS are located over $10 \mathrm{Km}$, airship itself leverages LTA technology being made of very high strength and lightweight materials, it is accompanied by advanced propulsion systems that maintain proper positioning, it is equipped with autonomous navigation, radio controlled command (TT\&C) and communications payload stabilization systems. The sample in Figure 2 also shows that airship located at $20 \mathrm{Km}$ position over Earth is able to cover about $400 \mathrm{Km}$ radius areas. The stratospheric airship is launched using a specified volume of helium separated from the air to maintain its shape. As the SPS rises the helium expands and at the proper altitude displaces all of the air within the SPS. Once it is in the stratosphere the SPS is remotely controlled and moved into determined position.

A combination of solar cells, batteries and fuel cells will power the SPS during its five-year planned deployment. Thus, the SPS also incorporates telemetry to remotely transmit data (TT\&C) and redundant systems to serve as back-up measures, then features that are designed to provide the airship with a high level of availability, reliability and safety. Thus, the SPS station is being designed to hold approximately $1,000 \mathrm{Kg}$ of communications payload capable of supplying focused fixed and mobile broadband, narrowband and wireless backbone services to approximately 3 million subscribers. The platform configurations can be dynamically changed in 
milliseconds to reallocate capacity as needed, such as to highly trafficked commuter routes during peak travel times, to business districts on weekdays or to stadiums during events.

As stated, there are two main solutions of SPS, aircraft and airships divided into four categories:

1. Manned stratospheric aircraft on fuel are flying in small circles for purpose as SPS and in any destination for observation and imaging applications around 48 hours or until fuel lasts;

2. Unmanned stratospheric aircraft on fuel, which can fly until fuel lasts;

3. Unmanned stratospheric aircraft on solar power can fly for minimum 6 month and get maintenance; and

4. Unmanned stratospheric airship on solar power can hover in certain position for minimum 6 months and has to be landed for maintenance, so in its place will be located another airship [1,2, $5]$.

\section{Applications and Service of Airship Constellation}

As already stated, the SPS is an air station located in stratosphere at an altitude of 20 to $50 \mathrm{~km}$ and at a specified, nominal, fixed point relative to the Earth, similar as GEO satellite. The SPS denomination was defined in the World Radio communications Conference (WRC) in 1997, in the Radio Regulations (RR) No. S1.66A as a station located on an object at an altitude of 20 to $50 \mathrm{~km}$ and at a specified, nominal, fixed point relative to the earth. [WRC-122, 97].

The SPS airships have to be the combination of the best characteristics of Terrestrial and Satellite systems as an alternative and complementary means of communications. In comparison to Terrestrial wireless technologies, SPS require considerably less communications infrastructure, they can serve potentially large coverage areas from a single site, the cell planning is more straight forward since they are able to provide line-of-sight (LOS) links and finally they are more cost effective.

All these characteristics make SPS suitable also for the provision of broadcast and multicast services, so they can be designed for the following applications:

1. Fixed and mobile communication systems for urban, suburban and rural areas;

2. Upgrading broadcast contents via Digital Video Broadcasting (DVB);

3. News gathering, IPTV, broadband, multimedia, very fast Internet, enterprises and private networks, and Service Providers Platforms (SPP);

4. Upgrading Global Navigation Satellite Systems (GNSS) for precise positioning and determination;

5. Enabling transmissions facilities for service of regional mobile Communication, Navigation and Surveillance (CNS);

5. Enhancing traffic control and management at sea, on the ground and in the air;

6. Improving Tracking and Monitoring of mobiles, peoples, animals and assets;

7. Providing remote sensing; weather observation; disaster monitoring, emergency response and security management;

9. Defense and Police Information Management.

These missions can be handled separately on an integrated basis, lowering the total costs. Some of them are associated with scientific research or with business case and others are directly related to security and military applications. The SPS airship networks are expected to be an attractive solution when there is a need for fast system deployment and redeployment for maintenance as no right-to-pass is required, by system components or remotely. The operation might start instantly with minimal configuration and initial costs, and be upgraded later, what in contrary the Satellite systems cannot be redeployed or upgraded during their lifespan $[1,2,5]$. 
Book of Proceedings

International Conference on Computer Science and Communication Engineering

\section{Airship Network Architectures and Characteristics}

The WCS technique known as cellular system is one of the fastest growing sectors of the communications industry, however WCS via SPS airships integrated with LEO, Medium Earth Orbit (MEO) and GEO satellite constellations recently become the focus of world's attention and future developments and improvements. The inter links between satellites and airships is the best way to provide reliable WCS networks for local and regional coverages.

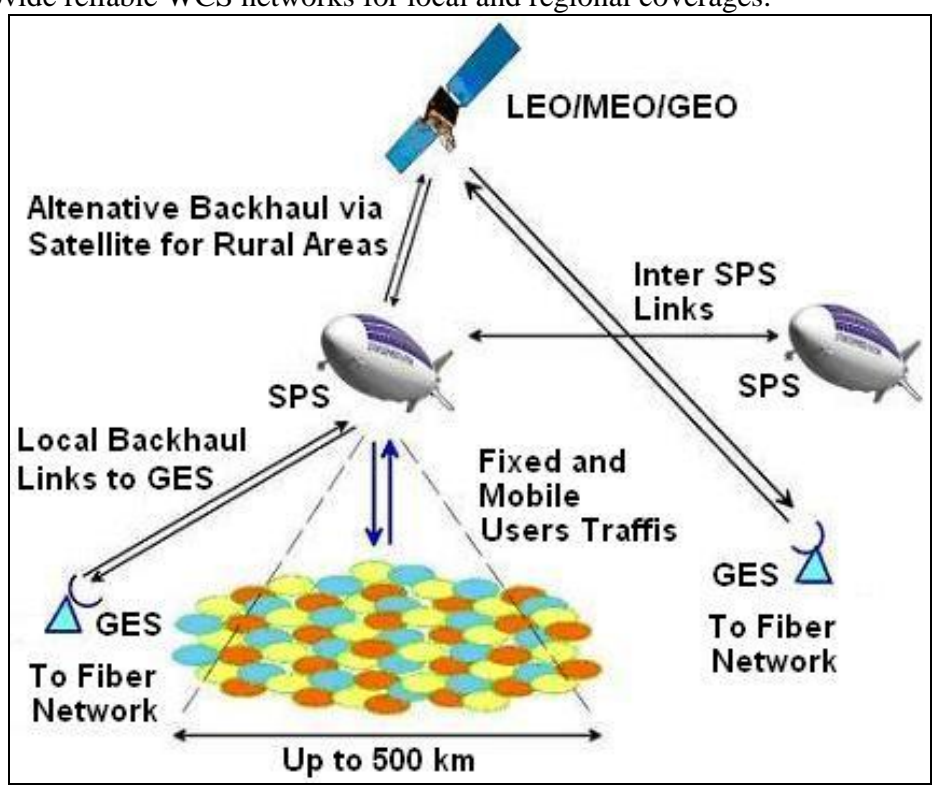

Figure 3. Integrated UAV/SCP and Satellite Networks [6]

The SPS airship constellations spread network coverage using inter platform links or alternative backhaul via satellite for remote areas. The SCP network contains large single-station able to provide coverage in range up to $400-600 \mathrm{~km}$, what depends on altitude, which is shown in Figure 3. That means that airships are providing local or regional backhaul links between user segment via SPS to the base station or Ground Earth Station (GES) connecting fiber optics or terrestrial communication networks.

The next important issues of employing the new WCS via SPS airship are high elevation angles, broad coverage, low propagation delay, very low-cost operation, easy and incremental deployment, ability to move around in emergency situation and can provide high-speed multimedia wireless communication service. The lower the minimum elevation angle, the larger the coverage environment but the propagation or blocking loss becomes high at the edge of the servicing area.

A practical minimum elevation angle for Broadband Wireless Access is $5^{\circ}$, while $15^{\circ}$ is more commonly considered in order to avoid excessive ground clutter problems. This implies that for a space platform positioned at an altitude of $20 \mathrm{~km}$ the radius of the coverage area is approximately $400-500 \mathrm{~km}$. Ground stations, which connect users and airships with other terrestrial networks, can be placed on roofs of buildings. For remote areas where there is no substantial terrestrial infrastructure, satellite systems can be used as backhaul. That is why most of stationary stratospheric platforms are to be located at the altitude above of about $25-30 \mathrm{~km}$ providing network coverage will up to approximately $500-600 \mathrm{~km}$. The airship units are seen as a middle ground between the terrestrial and satellite cases, and aims at exploiting potential 
benefits of intermediate altitudes between those used by the terrestrial and satellite technologies to provide broadband services to users, maximizing capacity and spectral efficiency, with a reduction in cost and complexity $[1,4,6]$.

\section{Airship Ground Segment}

The main question of the future SPS system is how many airship platforms are necessary to cover all particular territory or country and can this system became global? The recent experiments in Japan realized that 15 airships arrangement is necessary to cover all the territory of the Japanese mainland and islands for communications, broadcasting and broadband systems, under the condition of $22 \mathrm{~km}$ airship altitude with a minimum elevation angle of $10^{\circ}$. However, according to the territory size of South Africa, it will be necessary minimum 6 airship for complete coverage with same overlappings, which scenario is depicted in Figure 4. Airship is a cheaper solution than cellular systems, can cover vast teritiry and it does not require expensive basic GSM stations. During natural disaster or malicious intent base station can be destroyed, but airship will continue to work.

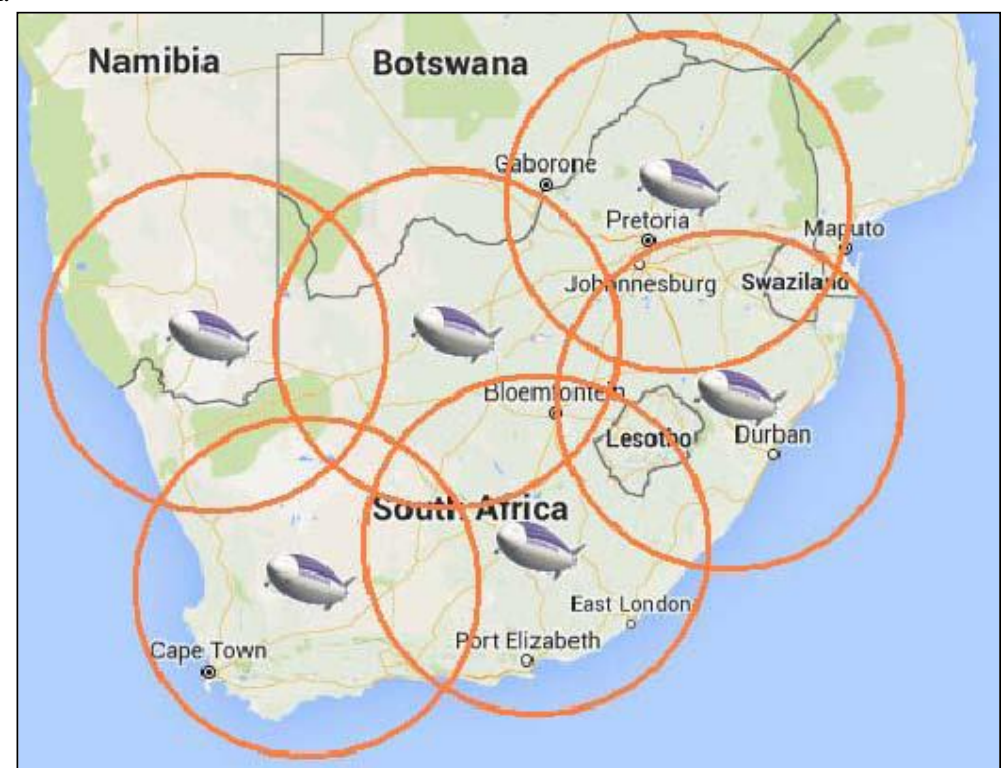

Fig. 4. Possible Coverage of South African Territory with 6 Airships [2]

A single airship is designed to cover a certain service area independently, so the service can be started from an area with a large density of population and number gradually increased service. The possibility of flexible business development is one of the main merits of SPS station and service area enables that one airship can cover generally depends on certain available numbers of ground Transmitter (Tx), Receiver (Rx), two-way direction antennas, methods of modulation and transmission and many other factors. Otherwise, the final intention of this project is to offer service to other regions and certain countries and if economical and technical evaluations are correct, it will provide global coverage. The concept of the system is very advanced in comparison with similar projects and has almost no disadvantages. 
Book of Proceedings International Conference on Computer Science and Communication Engineering

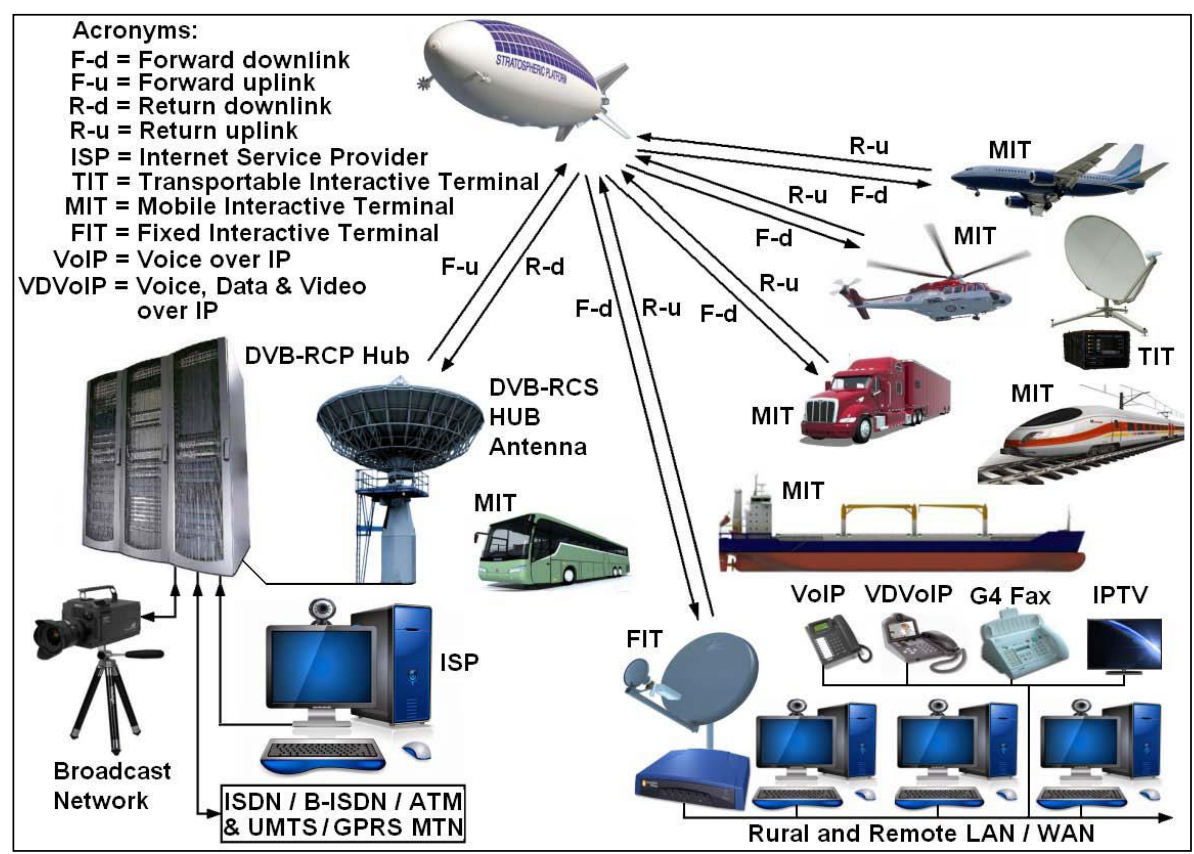

Fig. 5. Airship Fixed, Mobile and Transportable Communication Network [2]

The SPS airship is designed for fixed and mobile two-way communications and broadcasting similar to Digital Video Broadcasting-Return Channel via Satellite (DVB-RCS). The ground segment consists of GES or Gateways and fixed, semi fixed, transportable and mobile terminals, with onboard mobiles or fixed customer units corresponding auto tracking and focusing antenna systems for all applications, respectively. A complete Digital Video Broadcasting-Return Channel via Platform (DVB-RCP) with inter-platform links for fixed and mobile applications, which SPS network are illustrated in Figure 5. The DVB-RCP standards can provide broadcast service between ground telecommunication network and mobile or fixed customers via GES and airship SPS. In addition, the SPS airship network can be integrated with the US GPS and Russian GLONASS of Global Navigation Satellite System (GNSS) to provide their augmentation with mobile CNS solutions. In fact, airship systems for CNS will offer improved traffic control and management service for maritime, land, aeronautical and personal applications including GNSS access with enhanced safety and security in all transportation systems.

In fact, fixed ground terminals can be a self-contained mobile, transportable or fixed office with peripherals, such as PC configuration, modems, or as an integrated part of an advanced LAN/WAN, laptop, video, fixed telephone set in office or public and mobile or cellular phone equipment and photo camera connected via WiFi, WiMAX or Bluetooth facilities. At this point, mobile user terminals can be PC/laptop portable or fixed configurations interfaced to the SPS transceiver with adequate antennas or self-contained mobile or portable/in vehicle transceiver units with mobile auto tracking antenna and personal handheld terminals with built-in antenna $[2,7,8]$. 


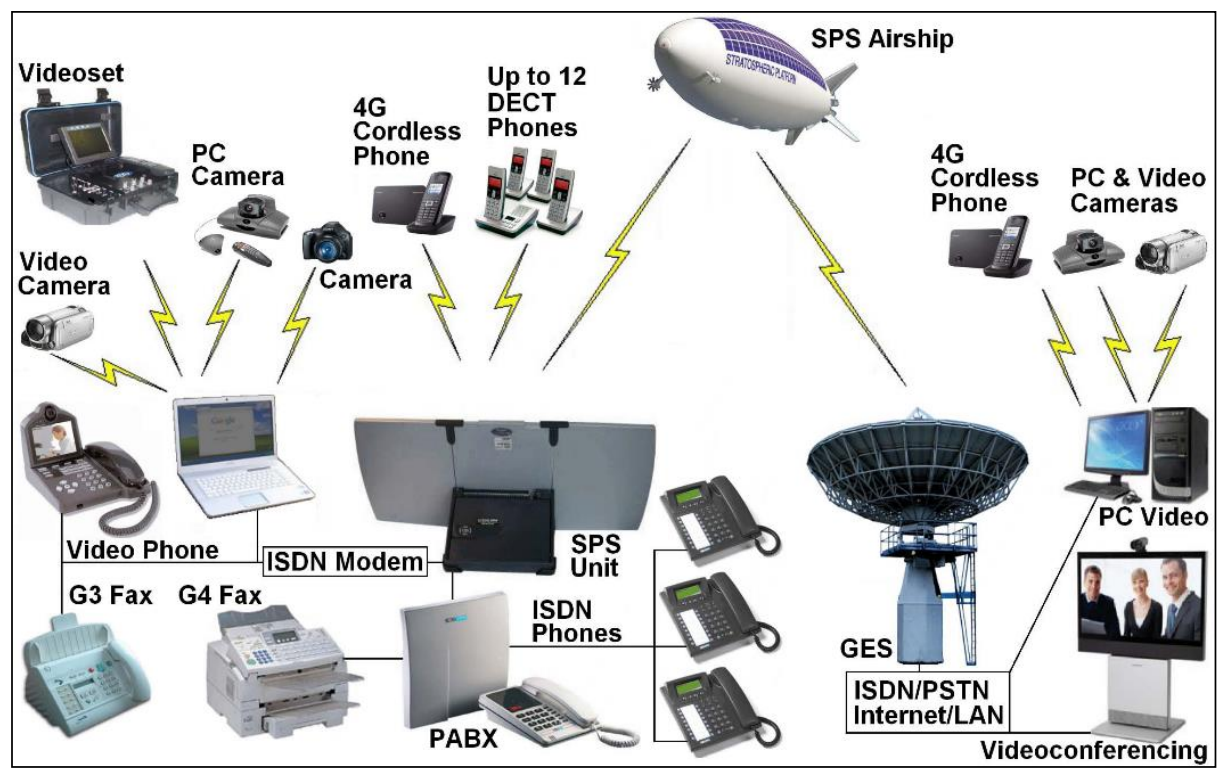

Fig. 6. Functional Block Diagram of Subscriber Equipment [2]

The total capacity of the airship network supported by a single airborne platform can be greater than $100 \mathrm{~GB} / \mathrm{s}$. This is comparable to terrestrial fiber-optic networks and can provide two-way broadband multimedia services normally available only via fiber-optic networks. Airships are maintained in the stratospheric zone constantly at an altitude of 20 to $25 \mathrm{~km}$, where the winds and other weather conditions are calm. The mean temperature is $-60 /-50^{\circ} \mathrm{C}$ and the atmospheric pressure is about $50 \mathrm{hPa}$. The altitude of $20 \mathrm{~km}$ is about 60 times higher than the Tokyo TV Tower so better LOS effects are obtained than cellular systems. Multi-path effects will be significantly reduced in most areas because of higher elevation angles.

A block diagram illustrated in Figure 6 is describing the customer equipment in remote offices or onboard mobiles, which are connected via GES to the ground telecommunication infrastructures. Thus, the SPS unit known as Consumer Premise Equipment (CPE) or Business Premise Equipment (BPE) is main equipment that is connecting all peripherals via RF Unit (RU). The RU modem contains the Microwave (MMW) Antenna and Transceiver, Network Interface Unit (NIU) and is connecting via ISDN PC or Laptop, ISDN phones, Private Automatic Branch Exchange (PABX), G3 and G4 Fax machines. The PC modem is connecting application terminals (peripherals) via WiFi, WiMAX and Bluetooth, such as Digital European Cordless Telecommunications (DECT) phones, 4G cordless phones, PC camera, photo camera, video camera and videoconference set.

The RU terminal consists of a small dual-feed antenna and MMW Transmitter (Tx) and Receiver $(\mathrm{Rx})$, which are mounted to the tracking antenna. The MMW Tx accepts an L-band (950 -1950 MHz) IF input signal from the NIU, translates it to MMW RF, amplifies the signal using a power amplifier to a transmit power level of $100-500 \mathrm{~mW}$ of power and feeds the antenna.

The MMW receiver couples signal from the antenna to an LNA, down converts the signal to an L-band IF and provides subsequent amplification and processing before outputting the signal to the NIU. Although the MMW transceiver is broadband, it typically will only process a single 40 $\mathrm{MHz}$ channel at any one time $[1,2,9]$. 
Book of Proceedings

International Conference on Computer Science and Communication Engineering

\section{Conclusion}

The new SPS infrastructures, whether aircraft or airship, are providing a number of unique attributes enabling them to offer a broad array of CNS services at low cost. The inexpensive SPS airship networks and gateways make it the lowest cost wireless infrastructure per subscriber conceived to date. The flexibility, reliability, enhanced capabilities and its low-cost will revolutionize telecommunications. Using several SPS stations, it is possible to provide regional or local (country-based) coverage. Coverage can be enlarged further and services enhanced by links between nearby aircraft or airships. Owing to high cost of satellite systems, the SPS networks are the best and very cost effective solutions for further development as a backbone to cellular and terrestrial networks and for coverage of rural areas in African countries.

\section{References}

1. Aragón-Zavala A., "High-Altitude Platforms for Wireless Communications", Wiley, Chichester, 2008.

2. Ilcev D.S., "Global Mobile Communications, Navigation and Surveillance (CNS)", DUT, Durban, South Africa, 2012.

3. Group of Authors, "Stratospheric Platforms", TAO, Tokyo, Japan, 2006.

4. Ilcev D. S., "Stratospheric Communication Platforms (SCP) as an Alternative for Space Program", AEAT Journal, Emerald, Bingley, 2011.

5. Grace D. and Mohorcic M., "Broadband Communications via High-Altitude Platforms", Wily, Chichester, 2011.

6. Ilcev D. S., "Global Mobile Satellite Communications for Maritime, Land and Aeronautical Applications", Springer, Boston, 2005.

7. Antonini M. and Others, "Stratospheric Relay: Potentialities of New Satellite-high Altitude Platforms Integrated Scenarios”, IEEEAC, 2003.

8. Sheriff E. R. and Hu Fun Y. "Mobile Satellite Communication Networks", Wiley, Chichester, 2001.

9. Evans B. \& Baughan K. "Vision of G4", Paper, Communication Engineering Journal, IEE, London, 2000. 